\title{
MEASUREMENT OF CHANNEL MOBILITY IN TOP CONTACT PENTACENE ORGANIC THIN FILM TRANSISTORS
}

\author{
PRAVINA RAJPUT ${ }^{1} \&$ VINAY K. SINGH ${ }^{2}$

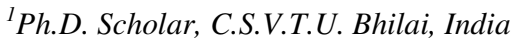 \\ ${ }^{2}$ Associate Professor, G.E.C. Jagdalpur, India
}

\begin{abstract}
A source voltage separation based method for the extracting the effective channel mobility in top contact pentacene organic thin film transistor is developed. Using the measured source voltage appear across the source is extracted. The new method facilitates mobility extraction in situations where the voltage appears across the source, making the mobility extraction easier and more accurate

KEYWORDS: OTFT, Pentacene, Contact Resistance, Effective Channel Mobility
\end{abstract}

Received: Jun 08, 2020; Accepted: Jun 28, 2020; Published: Aug 19, 2020; Paper Id.: IJMPERDJUN2020814

\section{INTRODUCTION}

Organic thin film transistors (OTFT) are being actively developed for a number of potential applications like sensors, inverters, radio frequency identification tags and displays on substrates such as glass, plastic, fabric and even paper [1]-[4]. There are significant improvement in performance over the last two decade, there are a number of challenging problems that still need to be addressed. Among them is high voltage required for operation of these transistors. A reduction in insulator thickness and use of insulators with high dielectric constant are among the potential approaches that are being explored to obtain low operating voltages [5]-[10]. Source resistance is one of the major challenge in organic thin film transistor. As a result, it is important to obtain its accurate value of channel mobility, so that factors contributing to it can be properly understood and managed. The method proposed in this work uses to measure the floating electrode voltage and then extracted voltage underneath the source as describe in Ref [11]. The Channel mobility is measured by subtraction of the source voltage from drain to source voltage.

\section{DEVICE FABRICATION}

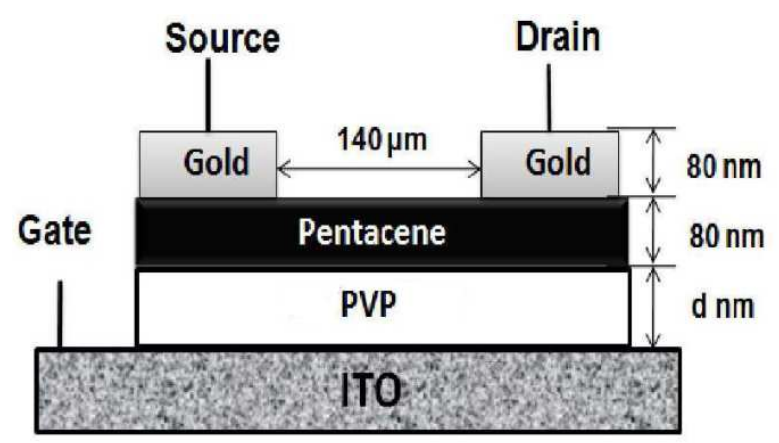

Figure 1: Schematic of Top Contact Bottom Gate Pentacene OTFTs Fabricated on PVP Dielectric. 
Figure 1 shows the schematic structure of a top contact OTFT with pentacene as semiconductor and poly (4vinylphonol) (PVP) as dielectrics. The devices were fabricated on indium-tin oxide (ITO) coated glass substrate where ITO was used as the gate electrode. Substrates were thoroughly cleaned using detergent, followed by ultra-sonic agitation in deionized water and standard RCA process. Subsequently, substrates were kept in an oven at $120^{\circ} \mathrm{C}$ for $1 \mathrm{hr}$ and then UVozone cleaning was per-formed for $10 \mathrm{~min}$ to remove any contaminants. PVP solutions with concentrations of $5.0 \mathrm{wt} \%$, and $10.0 \mathrm{wt} \%$ were prepared in poly(melamine-co-formaldehyde) solvent which was methylated using propylene glycol monomethyl ether acetate (PGMEA) ( $5 \mathrm{wt} \%$ ) as the cross linking agent. These solutions were spin coated at $1500 \mathrm{rpm}$ resulting in film thicknesses of $240 \mathrm{~nm}$ and $380 \mathrm{~nm}$ respectively. PVP films were dried at $180{ }^{\circ} \mathrm{C}$ for $1 \mathrm{hr}$ in high vacuum at a base pressure of $2 \times 10^{-6}$ Torr. This was followed by thermal evaporation of pentacene (evaporation rate: $0.4{ }^{\circ} \mathrm{A} / \mathrm{s}$, thickness: $90 \mathrm{~nm}$ ) at room temperature with the base pressure of $2 \times 10^{-6}$ Torr. Gold layer of $80 \mathrm{~nm}$ thickness was deposited using shadow mask for source and drain contacts. The channel length (L) and width (W) of the fabricated transistor were $140 \mu \mathrm{m}$ and $1 \mathrm{~mm}$ respectively. The current voltage characteristics of the fabricated devices were measured using keithley 4200-SCS semiconductor characterization system.

\section{Extraction of Channel Mobility}

In organic semiconductors, there are various issues which affect the estimation of the accurate channel mobility ( $\left.\mu_{\mathrm{ch}}\right)$ such as contact resistance, source resistance $\left(\mathrm{R}_{\mathrm{s}}\right)$ which play major important role.Instead of voltage drop across the channel, a significant voltage drop across the bulk $\left(\mathrm{V}_{\mathrm{Si}}\right)$ is observed. This affects the accurate estimation of the channel mobility. Ambiguity in measurement of the threshold voltage through the square root of drain current is also another factor that introduces the error in mobility calculation. Field effect mobility is an investigation tool to characterize the properties of semiconductors-insulators interfaces, such that the carrier's mobility as obtained from the analysis of the electrical behavior of the OTFT's architecture has become a key parameter in the evaluation of devices. For this purpose, accurate evaluation of the field effect mobility is very essential. The series contact resistance plays an important role on reducing the effective channel voltage that appears across the channel as some of the voltage drop across the source resistance. The effect of the contact resistance on the device performance will depend on the magnitude of the contact resistance relative to the channel resistance. The effective gate-to-source voltage that accounts for the calculation of the intrinsic channel mobility is given by the expression

$$
V_{G S}^{\prime}=V_{G s}-V_{s i}
$$

Where $\mathrm{V}^{\prime}{ }_{\mathrm{GS}}$ is the voltage apperar across the channel and $\mathrm{V}_{\mathrm{GS}}$ is the total potential applied across the gate to source. The voltage drop across the source resistance which gives

$$
V_{S i}=I_{D S} \times R_{S}
$$

The drain current (I' ${ }_{D S}$ ) in the saturation region can be modified by inserting the expression in Equation (1) in the saturation region drain current Equation, which gives

$$
I_{D S}^{\prime}=\frac{\mu W C_{i}}{L}\left(V_{G S}^{\prime}-V_{T}\right)^{2}
$$




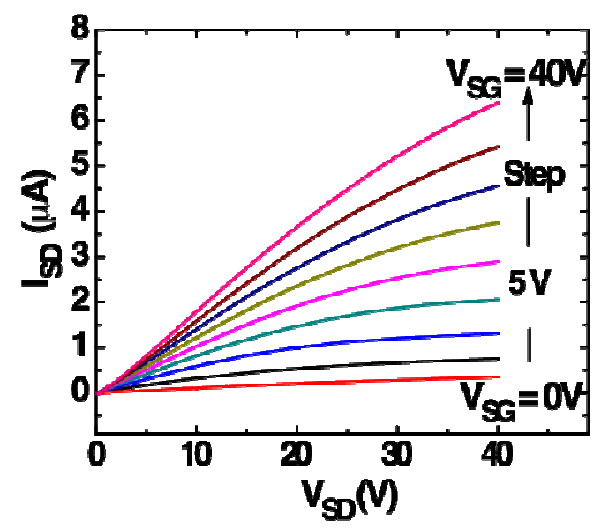

Figure 2

Fig. 2 Measured output characteristics of the fabricated OTFT. A mobility of $0.035 \mathrm{~cm}^{2} \mathrm{~V}^{-1} \mathrm{~s}^{-1}$ and threshold voltage of $-8.5 \mathrm{~V}$ was estimated from the transfer characteristics.

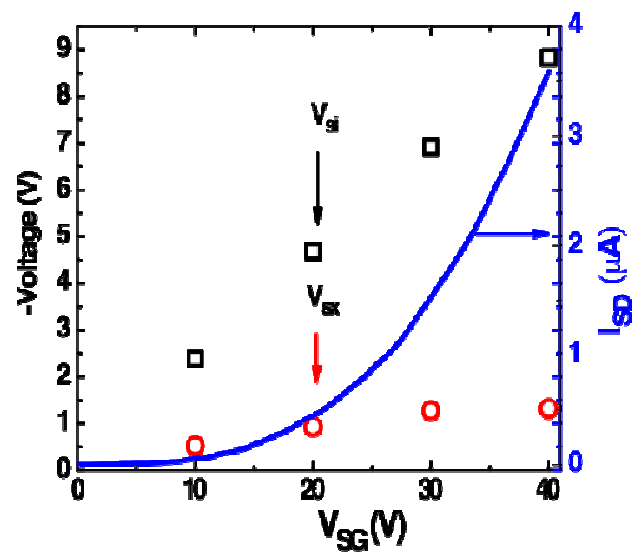

Figure 3

Fig. 3: Measured voltage (VSX) outside the source end, drain current, extracted value of voltage inside the source terminal (VSi). The source-to-gate voltage increasing from 0 to $40 \mathrm{~V}$ at constant source-to-drain bias voltage of $40 \mathrm{~V}$ for the PVP dielectric layer thicknessof $240 \mathrm{~nm}$.

In Fig. 3 Vsx shows measured voltage outside the source end, extracted value of voltage inside the source terminal ( VSi) for the source-to-gate voltage increasing from 0 to $40 \mathrm{~V}$ at constant source-to-drain bias voltage of $40 \mathrm{~V}$ for the PVP dielectric layer thickness of $240 \mathrm{~nm}$.

The measured drain current also indicated in Fig.3. The estimated value of voltage inside the source terminal (VSi) was performed using known value of measured voltage (VSX) [11]. The maximum product value of k.LS is 2 for the PVP dielectric layer thickness of $240 \mathrm{~nm}$. The maximum possible error is $10 \%$, which is possible for the measurement of the voltage $\left(\mathrm{V}_{\mathrm{Si}}\right)$, drop across the source resistance. 


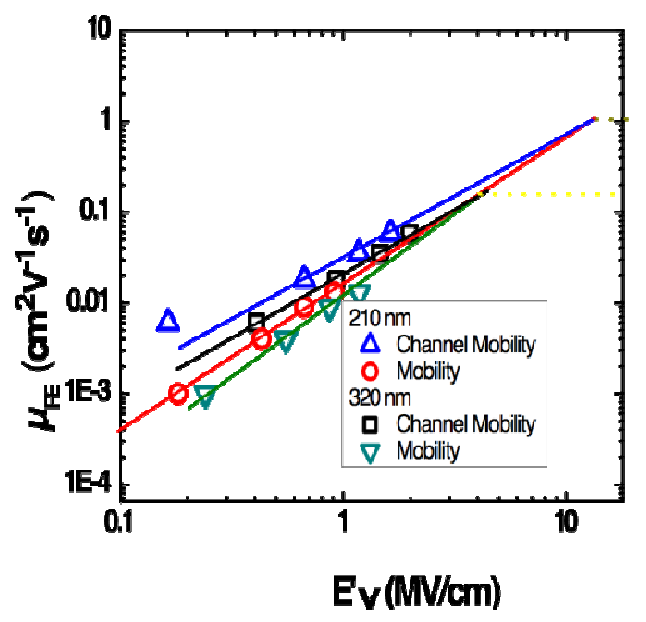

Figure 4

Figure 4: Variation of the field effect mobility $\left(\mu_{\mathrm{FE}}\right)$ with the vertical field $\left(\mathrm{E}_{\mathrm{Y}}\right)$ for two PVP layer thickness 240 $\mathrm{nm}$ and $380 \mathrm{~nm}$. Convergence of the field-dependent mobility was obtained by using the mobility extracted from the conventional method.

The channel mobility was estimated by using Eq. 3 and compared with the conventional approach as described earlier for the two different thicknesses $240 \mathrm{~nm}$ and $380 \mathrm{~nm}$ of PVP as a dielectric layer. Fig. 4 shows the extracted field effect mobility obtained for negligible gate leakage current (the drain-to-gate current ratio during the measurement of the family of output curves is $1 \times 10^{3}$ (minimum) to $1 \times 10^{5}$ (maximum). and then corrected from the contact voltage as described in the method and then plotted against vertical field using Eq. (4)

$$
E_{Y}^{F}=\frac{V_{G S}^{R}-V_{T}}{d}
$$

And then compared with the mobility obtained by the conventional method. The field effect mobility increased by increasing the gate voltage in both the thicknesses. If the comparison is performed at the same field, the mobility is found to be small as compared to the intrinsic channel mobility and the band mobility is higher for the intrinsic channel mobility case. The improvement in the band mobility is approximately 10 times larger as obtained by the conventional approach.

\section{CONCLUSIONS}

Measured Channel mobility in top contact pentacene organic thin film transistor is higher as compared to measured mobility using conventional method. Although improvement in the channel mobility is not significant as the source resistance of the OTFT is small. The improvement in the channel mobility may be significant if the source resistance of the device is large.

\section{REFERENCES}

1. E. J. Meijer, G. H. Gelinck, E. van Veenendaal, B. H. Huisman, D. M. de Leeuw, and T. M. Klapwijk, Scaling behavior and parasitic Series resistance in disordered organic field-effect transistors, Appl. Phys. Lett. 82, 4576 (2003).

2. G. Horowitz, P. Lang, M. Mottaghi, and H. Aubin, Extracting Parameters from the Current-Voltage Characteristics of Organic Field-Effect Transistors, Adv. Funct. Mater.14, 1069 (2004). 
3. Alphonse, Mathew, R. Ramesh Kumar, and M. Senthil Kumar. "Recent trends and advancements in the field of Micro electrical and mechanical systems (MEMS) technology." International Journal of Mechanical and Production Engineering Research and Development (IJMPERD) ISSN (P): 2249-6890; ISSN (E): 2249-8001 Vol 7: 479-488.

4. H. Klauk, G. Schmid, W. Radlik, W. Weber, L. S. Zhou, C. D. Sheraw, J. A. Nichols, and T. N. Jackson, Contact resistance in organic thin film transistors Solid-State Electron. 47, 297 (2003).

5. Chang, Fang-Wei, Jyh-Ling Lin, and Young-Huang Chou. "Study of 600 V-Class Super junction Metal-Oxide-Semiconductor Field-Effect Transistors with Termination of Trench Structure and Sipos. "International Journal of Electrical and Electronics Engineering Research (IJEEER) 6. 6, Dec 2016, 13-24

6. H. Klauk, M. Halik,U. Zschieschang,F. Eder,G. Schmid and D. Christine, Pentacene organic transistors and ring oscillators on glass and on flexible polymeric substrates, Appl. Phys. Lett. 82, 4175 (2003).

7. Kumar, Suresh, M L Aggarwal, and Lakhwinder Singh. "Reduced Weight and Cost in Smart Fork-Lift Using Nitione Way Helical Spring. "International Journal of Mechanical and Production Engineering Research and Development (IJMPERD) 10. 1, Feb 2020, 483-498

8. K. Nomura, H. Ohta, A. Takagi, T. Kamiya, M. Hirano and H. Hosono, Room-temperature fabrication of transparent flexible thin-film transistors using amorphous oxide semiconductors, Nature 432, 488 (2004).

9. L. Burgi, T. J. Richards, R. H. Friend, and H. Sirringhaus, Close look at charge carrier injection in polymer field-effect transistors, J. Appl Phys. 94, 6129 (2003).

10. P. F. Baude, D. A. Ender, M. A. Haase, T. W. Kelley, D. V. Muyres, and S. D. Theiss, Pentacene-based radio-frequency identification circuitry, Appl. Phys. Lett. 82, 3964 (2003).

11. P. V. Necliudova, M. S. Shur, D. J. Gundlach and T. N. Jackson, Contact resistance extraction in pentacene thin film transistors J. Appl. Phys. 93, 6594 (2000)

12. T. Li, P. P. Ruden, I. H. Campbell, and D. L. Smith, Investigation of bottom-contact organic field effect transistors by twodimensional device modeling J. Appl. Phys. 93, 4017 (2003).

13. Vinay K. Singhand BaquerMazhari, “ Impact of Scaling of Dielectric Thickness on Mobility in Top-Contact Pentacene Organic Thin Film Transistors" Journal of Applied Physics, 111, 034905 (2012).

14. Vinay K. Singh and BaquerMazhari, “Measurement of Threshold Voltage in Organic Thin Film Transistors " Applied Physics Letter, 102, 253304 (2013).

15. Dabbagh, Balkees M. Al, Hanaa J. Al Shimary, and Rana M. Salih. "Separation of Oil/Water System by Polymeric the Super Hydrophobicmaterial for Civil Application."International Journal of Mechanical and Production Engineering Research and Development (IJMPERD) 8.2, Apr 2018, 1221-1226

16. Vinay Kumar Singh, Ashish Agrawal and BaquerMazhari“ Measurement of Source Resistance in Top-Contact Organic Thin Film Transistors" IEEE Electron Device Letter Vol. 33, No. 3, March (2012). 

